\title{
Prediction models of health-related quality of life in different neck pain conditions: a cross-sectional study
}

This article was published in the following Dove Press journal:

Patient Preference and Adherence

\author{
Hector Beltran-Alacreu ${ }^{1,2}$ \\ Ibai López-de-Uralde- \\ Villanueva ${ }^{1,2}$ \\ César Calvo-Lobo ${ }^{3}$ \\ Roy La Touche ${ }^{1,2,4}$ \\ Roberto Cano-de-la- \\ Cuerda ${ }^{5}$ \\ Alfonso Gil-Martínez ${ }^{1,2,4}$ \\ David Fernández-Ayuso ${ }^{6}$ \\ Josué Fernández- \\ Carnero ${ }^{2,4,5}$ \\ 'Departamento de Fisioterapia, \\ Centro Superior de Estudios \\ Universitarios La Salle, Universidad \\ Autónoma de Madrid, Spain; ${ }^{2}$ Motion \\ in Brains Research Group, Institute \\ of Neuroscience and Movement \\ Sciences (INCIMOV), Centro \\ Superior de Estudios Universitarios \\ La Salle, Universidad Autonóma de \\ Madrid, Spain; ${ }^{3}$ Nursing and Physical \\ Therapy Department, Institute of \\ Biomedicine (IBIOMED), Faculty of \\ Health Sciences, Universidad de León, \\ Ponferrada, León, Spain; ${ }^{4}$ Hospital La \\ Paz Institute for Health Research, \\ IdiPAZ, Madrid, Spain; ${ }^{5}$ Department \\ of Physical Therapy, Occupational \\ Therapy, Rehabilitation and Physical \\ Medicine, Universidad Rey Juan \\ Carlos, Alcorcón, Madrid, Spain; "'San \\ Juan de Dios" School of Nursing and \\ Physiotherapy, Pontifica de Comillas \\ University, Madrid, Spain
}

Correspondence: César Calvo-Lobo Nursing and Physical Therapy Department, Institute of Biomedicine (IBIOMED), University of León, Av Astorga, s/n, 2440I Ponferrada, León, Spain

Tel +34987442053 ext 2053

Email ccall@unileon.es
Purpose: The main aim of the study was to predict the health-related quality of life (HRQoL) based on physical, functional, and psychological measures in patients with different types of neck pain (NP).

Materials and methods: This cross-sectional study included 202 patients from a primary health center and the physiotherapy outpatient department of a hospital. Patients were divided into four groups according to their NP characteristics: chronic (CNP), acute whiplash (WHIP), chronic NP associated with temporomandibular dysfunction (NP-TMD), or chronic NP associated with chronic primary headache (NP-PH). The following measures were performed: Short Form-12 Health Survey (SF-12), Neck Disability Index (NDI), visual analog scale (VAS), State-Trait Anxiety Inventory (STAI), Beck Depression Inventory (BECK), and cervical range of movement (CROM).

Results: The regression models based on the SF-12 total HRQoL for CNP and NP-TMD groups showed that only NDI was a significant predictor of the worst HRQoL ( $48.9 \%$ and $48.4 \%$ of the variance, respectively). In the WHIP group, the regression model showed that BECK was the only significant predictor variable for the worst HRQoL ( $31.7 \%$ of the variance). Finally, in the NP-PH group, the regression showed that the BECK, STAI, and VAS model predicted the worst HRQoL (75.1\% of the variance).

Conclusion: Chronic nonspecific NP and chronic NP associated with temporomandibular dysfunction were the main predictors of neck disability. In addition, depression, anxiety, and pain were the main predictors of WHIP or primary headache associated with CNP.

Keywords: quality of life, neck pain, disability, depression, anxiety

\section{Introduction}

Neck pain (NP) is a common problem that most people experience at some point in their lives; it is also frequently encountered in clinical practice. ${ }^{1-5}$ The impact of NP is well known and can be a socially related problem for families, work, the health system, and the economy. ${ }^{3-6}$ In Spain, a recent study reported that the prevalence of this disease was increased from 2008/9 to 2011/12, particularly isolated NP ( $7.86 \%$ vs $8.56 \%)$ as well as NP with lower back pain $(10.61 \%$ vs $11.12 \%)$ in the last 3 years. ${ }^{4}$ The prevalence of NP is generally higher in women than men and usually increases with age; there is evidence that the younger population has a better prognosis for improvement. ${ }^{4,5}$ Given recent research, the relationship between different clinical conditions and NP (or neck disability) have been observed, including temporomandibular dysfunction (TMD), primary headaches, and/or whiplash..$^{7-10}$ According to recent research, NP with migraine is more likely to be a component of the attack than 
a related symptom. ${ }^{11}$ Different studies show data that are in agreement with this correlation, ie, between NP and primary headaches. $^{12-15}$

People with NP may have associated psychological factors, including anxiety, depression, catastrophizing, and fear of movement. ${ }^{16}$ A survey revealed that $20 \%$ of patients with chronic pain disorders are also diagnosed with depression. ${ }^{17}$ There is growing evidence that psychological factors influence the course of NP and become potential risk factors for chronic pain. ${ }^{16,18}$ People with NP and various psychological factors reported greater disability, including increased risk of chronic disability. ${ }^{19,20}$ However, several studies found that patients with whiplash-related disorders had psychological issues, such as post-traumatic stress symptoms, catastrophizing about pain, and symptoms of depression and lower expectations for recovery, which then predicts a poor recovery.,21-23

In recent years, the literature indicates that these factors directly affect the health-related quality of life (HRQoL) for patients with chronic pain. ${ }^{1724-31} \mathrm{HRQ}$ oL has become increasingly important, as it combines the evaluation and treatment of the patient's perception of the disease's impact; this is especially relevant for patients with chronic diseases and disabilities. ${ }^{17,24-31}$ With respect to NP, which can similarly be chronic and disabling, evidence about HRQoL in the general population is low, but there are studies that show how people suffering with NP also have impaired HRQoL; ;6,27,31,32 this suggests that those with NP have limitations in their social sphere and that physical activity and the capacity to work is reduced. ${ }^{27}$ A high level of neck disability is also associated with higher levels of NP and a generally poor HRQoL, along with a worse mental component of HRQoL. ${ }^{33}$ However, in the recent literature, there are controversial conclusions regarding NP and HRQoL. Lin et al found that those with NP had a poorer HRQoL, with a lower score on the mental component of the Short Form-36 Health Survey (SF-36). ${ }^{31}$ Nolet et al ${ }^{26}$ found that NP was negatively associated with physical issues, but not necessarily with the mental component of HRQoL. Musculoskeletal disorders related to maxillofacial and head and NP may produce physical impairment, such as movement alterations or regional anatomical disorders; these include functional limitations, such as disability in daily activities, and also affect the patients' quality of life (QoL). ${ }^{34}$

The hypothesis is that predictors for HRQoL can be different, depending on the type of NP. The aim of this study was to analyze this variable and explore its correlation with physical, functional, and psychological measures and be better able to determine which predictive factors are present in patients with certain types of NP and a lower QoL.

\section{Materials and methods}

This research was a cross-sectional study to assess how NP affects QoL and whether different physical and psychological variables also influence it. Our investigation was conducted according to the STrengthening the Reporting of OBservational studies in Epidemiology (STROBE) statement, ${ }^{62}$ which was defined between 2013 and 2016.

The research team included 10 physiotherapists, each having 5-10 years of clinical experience in orthopedic manual therapy. One training session reviewed how to perform the procedure along with measurements of cervical range of movement (CROM).

\section{Ethics approval and consent to participate}

The Ethics Committee for Clinical Research of Hospital Universitario La Paz (Madrid, Spain) (Code PI-1241) approved this study. All voluntary participants signed their written consent form before the study began. Research ethical standards on human experimentation beings were considered according to the World Medical Association of Helsinki Declaration, the Europe Council Convention on Human Rights \& Biomedicine, the UNESCO Universal Declaration on the Human Genome and Human Rights as well as other relevant national requirements.

\section{Participants}

Two hundred and two patients participated in this study, recruited via referral from the physiotherapy outpatient department of the Primary Health Care Centre of Coslada (Madrid, Spain) and the Hospital Universitario La Paz (Madrid, Spain). We included subjects who were between 18 and 65 years old; they understood, wrote, and spoke Spanish correctly, and complained of pain localized to the neck region. Patients were divided into four groups according to their NP characteristics: chronic NP (CNP, >12 weeks), NP associated with acute whiplash (WHIP), chronic NP associated with TMD (NP-TMD), and chronic NP associated with chronic primary headache (NP-PH). ${ }^{35}$ Patients with NP-TMD and NP-PH were recruited from specific units by a medical specialist, who selected them according to the Diagnostic Criteria for TMD and the International Headache Classification, respectively. ${ }^{36,37}$ Participants were not considered if they reported any of the following conditions: physical therapy 
in the previous 3 months, psychiatric disorders, a medical red flag history (tumors, fractures, metabolic diseases, rheumatoid arthritis, or osteoporosis), NP with cervical radiculopathy, NP associated with externalized cervical disc herniation, fibromyalgia syndrome, previous neck surgery, or NP accompanied by vertigo, primarily caused by vertebrobasilar insufficiency. To avoid the overlap of fibromyalgia with a nonspecific chronic pain diagnosis, a physician conducted the test for a clinical diagnosis of fibromyalgia, according to the American College of Rheumatology. ${ }^{38}$

After checking that each of the subjects met the inclusion criteria (and did not include any of the exclusion criteria), they were asked to read and give their informed consent.

\section{Outcome measures}

The HRQoL was the selected primary outcome. The SF-12 v 2 is a multipurpose, short-form survey that includes 12 items (taken directly from the SF-36 v 2). The SF-12 v 2 yields 8 scale scores (physical functioning [PF], role-physical [RP], bodily pain [BP], general health [GH], vitality [VT], social functioning [SF], role-emotional [RE], and mental health $[\mathrm{MH}])$. Four scale scores (PF, RP, RE, and MH) were calculated using two items, whereas the remaining scales (BP, GH, VT, and SF) were represented by one item. Twelve items were derived from two summary measures (ie, the physical component summary and the mental component summary). ${ }^{39,40}$ This questionnaire showed strong psychometric properties and a correlation of 0.94 between SF-36 and SF-12 in the Spanish population. ${ }^{41,42}$ Several worded items were recoded, with higher scores indicating a better condition. Scale scores were transformed to a $0-100$ range, based on the scoring manual.

\section{Neck Disability Index (NDI)}

The NDI is a validated 10-item questionnaire, with each item rated on a 6-point scale. ${ }^{43}$ The NDI has sufficient support in the field as the most commonly used instrument for NP, ${ }^{43-45}$ along with a Spanish form of the index. ${ }^{46}$ We divided the sample into five groups of disabilities: scores $<4$ indicate no disability, 5-14 mild disability, 15-24 moderate disability, 25-34 severe disability, and $>35$ complete disability. In this study, the complete disability group was not included, due to the small sample size.

\section{Visual analog scale (VAS)}

Pain intensity was measured via the VAS, a $100 \mathrm{~mm}$ horizontal line with pain descriptors marked "no pain" on the left side and "the worst pain imaginable" on the right side.
The patient was asked for pain intensity by marking the VAS with a perpendicular line (in that it is a reliable and valid measure of pain). ${ }^{47,48}$

\section{State-Trait Anxiety Inventory (STAI)}

The STAI was used to measure anxiety in patients with NP. It is a questionnaire measuring trait anxiety (a personality factor that predisposes a patient to experience anxiety) and the anxiety state (environmental factors that protect or generate anxiety). Each of the two subscales (trait anxiety and state anxiety) consists of 20 items, scored from 0 (none) to 3 (very much). ${ }^{49}$ The two subscales have high convergent validity, when combined with other measures of related anxiety. ${ }^{50}$

\section{Beck Depression Inventory (BECK)}

The BECK is one of the most widely used screening tools for measuring the severity of depression in patients over 13 years of age. The inventory is composed of items related to depressive symptoms, such as hopelessness and irritability, specific and persistent thoughts (guilt or feelings of being punished), and physical symptoms (fatigue, weight loss, and lack of sexual interest). BECK contains 21 items and identifies symptoms and attitudes associated with depression. The respondent must recall the relevance of each statement on the day of testing: mood, pessimism, sense of failure, lack of satisfaction, guilt, sense of punishment, self-hatred, selfaccusations, self-punitive wishes, crying spells, irritability, social withdrawal, indecisiveness, body image dysmorphia, work inhibition, sleep disturbance, fatigue, appetite and weight loss, somatic preoccupation, and loss of libido. Each item is evaluated on a severity scale ranging from 0 to 3 , with a total score ranging from 0 to 63 : a score of $0-10$ on the BDI indicates absent or minimal depression, 11-18 mild to moderate depression, 19-29 moderate depression, and 30-63 severe depression. This assessment was previously used in those with NP. ${ }^{25,51,52}$

\section{Cervical range of movement}

Active ranges of movement of the cervical spine were evaluated with CROM, a test consisting of three inclinometers attached to a lightweight, plastic frame, and secured with fastening straps. The protocol involves a sequence of three measurements, with an interval of 30 seconds between each one. The CROM test has good intra-rater reliability for subjects with and without NP (intraclass correlation coefficient $=$ 0.87-0.94 in asymptomatic subjects and intraclass correlation coefficient $=0.88-0.96$ in NP subjects).${ }^{53}$ The following 
movements were measured: flexion and extension, right and left lateral flexion, and right and left rotation.

\section{Potential confounders}

Sociodemographic data such as gender and age were assessed as potential confounders.

\section{Procedure}

The data collection was performed in a room in which only the assessor and patient were present. The assessor first explained the experiment, so that patients could give their informed consent. The questionnaires were filled out, and the CROM test was performed. The study was carried out before patients began treatment with the physiotherapy service.

\section{Biases}

To avoid potential bias, a researcher was in charge of recruiting and informing patients about the study, understanding the clinical status of the subject, and explaining that the patient should not discuss their kind of pain with the assessor (who would be taking the measurements). The assessors were all responsible for collecting outcome data without being aware of the group of subjects. Data were collected from different centers, and this information was sent to another researcher responsible for conducting the analysis.

\section{Sample size}

Sample size and power calculations were performed with appropriate software (G*Power 3.1). ${ }^{54}$ This study was based on a model of linear multiple regression, and HRQoL was the primary outcome, with an effect size of 0.35 . Given an alpha level of 0.05 and a power of 0.85 , four groups were generated with a total sample size of 176 . The groups included CNP, WHIP, NP-PH, and NP-TMD, with a minimum of 44 participants per group.

\section{Data analysis}

Statistical analysis was performed with the Statistical Package for the Social Sciences, version 20 (IBM Corporation, Armonk, NY, USA). To test the relationship between QoL, psychological symptoms, and other variables (NDI, VAS, STAI, and BECK), we performed a one-way ANOVA to verify which ones entailed statistically significant effects and performed the correlation test. Pearson's correlation was calculated separately for CNP, WHIP, NP-TMD, and NP-PH groups. For all analyses, statistical significance was set at $P<0.05$.
HRQoL SF-12 v 2 was the independent variable in the logistic regression analysis and was used to examine associations between different subgroups of patients assessed by STAI, BECK, VAS, and NDI. Selection was constrained by the number of possible dependent variables, since the final groups with CNP, WHIP, NP-PH, and NP-TMD included $\mathrm{N}=50, \mathrm{~N}=54, \mathrm{~N}=53$, and $\mathrm{N}=45$, respectively.

\section{Results}

\section{Participants and descriptive data}

A total of 202 patients with NP met the inclusion criteria and agreed to enter the study, leaving a sample of $\sim 50$ per group (except NP-TMD, $n=45$ ). The mean age of the sample was $35.91 \pm 13.36$ years, with most of them being female (74.6\%). The descriptive characteristics of the participants are shown in Table 1.

\section{Main results}

Associations (Pearson correlation coefficients) between the (SF-12 v 2 physical, SF12 v 2 mental, SF-12 v 2 total) QoL variables and VAS, NDI, BECK, and STAI are listed in Table 2. Considering that the values of $r$ require a moderate or high correlation, they were between $0.50-0.70$ and $0.70-0.90$, respectively, ${ }^{55}$ a strong correlation was observed between the NDI and SF-12 v 2 physical in the CNP $(r=-0.728)$, WHIP $(r=-0.515)$, and NP-TMD $(r=-0.583)$ groups, and between depression and SF-12 v2 total in the NP-PH $(r=-0.814)$ and WHIP ( $r=-0.575)$ groups. For CROMs, the strongest correlations were observed in the CNP group: between SF-12 v 2 physical with flexion and extension $(r=0.563$ and $r=0.517$, respectively) and SF-12 v 2 total with flexion $(r=0.59)$. In the NP-TMD group, we found a correlation between SF-12 v 2 physical and flexion $(r=0.493)$. No correlations were found in the WHIP or NP-PH groups for CROMs.

Regression models for criteria variables (SF-12 v 2 HRQoL) are presented in Table 3. The regression models used different predictors for a negative HRQoL: NDI predicted poor HRQoL for the CNP group (48.9\% of variance), and BECK predicted poor HRQoL for the WHIP and NP-PH groups (31.7\% and $65.9 \%$ of variance, respectively). For the NP-PH group, BECK and STAI together predicted 70.3\% of the variance, while BECK, STAI, and VAS all predicted $75.1 \%$ of the variance. In the NP-TMD group, NDI was the only significant predictive variable ( $48.4 \%$ of variance).

\section{Discussion}

In this cross-sectional study, we predicted the HRQoL for different types of NP (nonspecific chronic pain, acute 
Table I Characteristics of the groups

\begin{tabular}{|c|c|c|c|c|}
\hline & $\begin{array}{l}\text { CNP } \\
(n=50)\end{array}$ & $\begin{array}{l}\text { WHIP } \\
(n=54)\end{array}$ & $\begin{array}{l}\text { NP-PH } \\
(n=53)\end{array}$ & $\begin{array}{l}\text { NP-TMD } \\
(n=45)\end{array}$ \\
\hline Age (years) & $29.56 \pm 10.62$ & $32.46 \pm 10.01$ & $48.62 \pm 13.22$ & $36.75 \pm 10.79$ \\
\hline Gender, female, n (\%) & $36(72.0)$ & $25(46.3)$ & $49(92.5)$ & $4 I$ (9I.I) \\
\hline Male, n (\%) & $14(28)$ & $29(53.7)$ & $4(7.5)$ & $4(8.9)$ \\
\hline Total SF-I2 (\%) & $64.28 \pm 21.93$ & $36.95 \pm 19.47$ & $41.46 \pm 19.24$ & $61.62 \pm 22.05$ \\
\hline Physical SF-I2 (\%) & $67.05 \pm 26.65$ & $31.15 \pm 17.67$ & $37.08 \pm 23.84$ & $60.67 \pm 26.64$ \\
\hline Mental SF-I2 (\%) & $61.52 \pm 23.19$ & $42.75 \pm 25.62$ & $45.85 \pm 20.1$ & $62.58 \pm 22.76$ \\
\hline NDI (0-50) & $13.06 \pm 6.86$ & $29.76 \pm 9.05$ & $18.89 \pm 8.25$ & $12.82 \pm 5.14$ \\
\hline VAS (mm) & $4 I . I \pm 20.04$ & $60.38 \pm 24.58$ & $60.4 \pm 18.67$ & $44.23 \pm 21.68$ \\
\hline BECK (0-63) & $8.14 \pm 5.49$ & $14.57 \pm 9.38$ & $18.58 \pm 10.49$ & $15.4 \pm 9.59$ \\
\hline STAI (0-60) & $26.2 \pm 4.08$ & $25.72 \pm 6.9$ & $24.86 \pm 6.85$ & $24.33 \pm 6.37$ \\
\hline \multicolumn{5}{|l|}{ CROMs (grades) } \\
\hline Flexion & $47.72 \pm 14.36$ & $25.82 \pm 10.58$ & $47.02 \pm 9.37$ & $48.47 \pm 14.55$ \\
\hline Extension & $55.69 \pm \mid 4.11$ & $25.3 \pm 12.7$ & $63.97 \pm 15.02$ & $65.8 \pm 16.19$ \\
\hline Left rotation & $59.04 \pm 12.5$ & $28.95 \pm 13.74$ & $61.68 \pm 9.43$ & $64.81 \pm 11.26$ \\
\hline Right rotation & $57.32 \pm 10.94$ & $27.56 \pm 13.11$ & $62.8 \pm 8.76$ & $64.31 \pm 7.68$ \\
\hline Left lateral flexion & $39.45 \pm 8.84$ & $23.17 \pm 8.11$ & $40.25 \pm 7.00$ & $4 I .23 \pm 8.71$ \\
\hline Right lateral flexion & $36.87 \pm 9.12$ & $24.33 \pm 8.07$ & $37.76 \pm 6.89$ & $38.58 \pm 8.4$ \\
\hline
\end{tabular}

Note: Values are mean \pm SD and $n(\%)$.

Abbreviations: CNP, chronic neck pain; WHIP, neck pain associated with acute whiplash; NP-PH, neck pain associated with chronic primary headache; NP-TMD, neck pain associated with temporomandibular dysfunction; NDI, Neck Disability Index; VAS, visual analog scale; BECK, Beck Depression Inventory; STAI, State-Trait Anxiety Inventory; CROM, cervical range of movement; SF-12, Short Form- 12 Health Survey.

whiplash, chronic migraine subjects with NP, and temporomandibular pain associated with NP) based on neck disability, pain intensity, anxiety, and depression. Our results showed differences in NP types analyzed, and we provided data that indicated (despite having common pain in the cervical region) the correlations and predictors of HRQoL were different: neck disability for the CNP and NP-TMD groups and depression and anxiety for the WHIP and NP-H groups. The literature shows that HRQoL in nonspecific NP was not screened if subjects had migraines, primary headaches, or TMD..$^{26,31,33}$ This is the first study to observe the differences in the physical and mental spheres of HRQoL by comparing different patient groups with different types of NP. These findings may be based on CNP and NP-TMD, showing an association with the patients' disability; they could also be influenced by work activity and modified HRQoL prediction models. ${ }^{56}$ Depression and anxiety may lead to chronic headaches from whiplash injury that produce mild to moderate pain. ${ }^{57}$

Regarding the CNP group, Leaver et $\mathrm{al}^{33}$ indicated that poor GH, higher pain levels, and lower SF-12 mental component scores were independently associated with higher levels of disability. The SF-12 mental portion showed a negative correlation with psychological measurements, as supported by previous studies in which patients' $\mathrm{MH}$, as a function of CNP, was associated with various psychological factors. ${ }^{31}$ Nolet et al ${ }^{26}$ found that NP was negatively correlated with physical but not with mental HRQoL - possibly since they used depression as a confounding variable, although our study did not. Our results indicate that the two areas of HRQoL are negatively correlated with depression in patients with chronic NP.

Regarding the WHIP group, Kenardy et $\mathrm{a}^{58}$ reported that patients with traffic crash-related injuries were affected with poor physical and mental HRQoL when comorbid psychological disorders and intense pain were present. Psychological disorders are in line with our study, but pain levels were not correlated with HRQoL. In contrast, Kenardy et $\mathrm{a}^{58}$ observed a correlation between pain levels and HRQoL, likely due to characteristics of their sample; they used a different tool to measure pain, as their subjects were chronic, whereas our subjects suffered mainly from acute pain. A recent study by Williamson et $\mathrm{a}^{19}$ found an association between disability and psychological and behavioral factors in WHIP. Our data also support this, as we report negative correlations between disability and spheres of HRQoL, pain levels, along with anxiety.

Lantéri-Minet et $\mathrm{al}^{59}$ found reduced HRQoL with more pronounced disability; they were associated with depression and anxiety in subjects with migraine but were not for those with depression alone. They also observed that depression was associated with low levels of HRQoL in the physical 
Table 2 Correlation coefficients between measures

\begin{tabular}{|c|c|c|c|c|c|c|c|}
\hline & $\begin{array}{l}\text { SF-12 } \\
\text { total }\end{array}$ & $\begin{array}{l}\text { SF-12 } \\
\text { physical }\end{array}$ & $\begin{array}{l}\text { SF-12 } \\
\text { mental }\end{array}$ & NDI & VAS & STAI & BECK \\
\hline \multicolumn{8}{|l|}{ Chronic neck pain } \\
\hline SF-I 2 total & 1 & $0.896 * *$ & $0.861 * *$ & $-0.682 * *$ & -0.137 & -0.191 & $-0.556 * *$ \\
\hline SF-I 2 physical & & 1 & $0.546 * *$ & $-0.728 * *$ & -0.056 & -0.141 & $-0.493 * *$ \\
\hline SF-1 2 mental & & & 1 & $-0.453 * *$ & -0.201 & -0.199 & $-0.486 * *$ \\
\hline NDI & & & & 1 & 0.142 & 0.227 & $0.575^{* *}$ \\
\hline VAS & & & & & 1 & 0.118 & 0.179 \\
\hline STAI & & & & & & 1 & $0.405^{* *}$ \\
\hline BECK & & & & & & & 1 \\
\hline \multicolumn{8}{|l|}{ Acute whiplash } \\
\hline SF- 12 total & 1 & $0.85 \mathrm{I} * *$ & $0.932 * *$ & $-0.468 * *$ & -0.083 & -0.177 & $-0.575^{* *}$ \\
\hline SF-12 physical & & 1 & $0.604 * *$ & $-0.515 * *$ & -0.101 & -0.271 & $-0.414 * *$ \\
\hline SF-I 2 mental & & & I & $-0.355 * *$ & -0.057 & -0.082 & $-0.588 * *$ \\
\hline NDI & & & & I & $0.338^{*}$ & 0.114 & $0.529 * *$ \\
\hline VAS & & & & & 1 & -0.049 & 0.292 \\
\hline STAI & & & & & & 1 & -0.016 \\
\hline BECK & & & & & & & I \\
\hline \multicolumn{8}{|c|}{ Neck pain with primary headache } \\
\hline SF-I 2 total & I & $0.897^{* *}$ & $0.85 I^{* *}$ & $-0.476 * *$ & -0.29 & -0.151 & $-0.814 * *$ \\
\hline SF-I 2 physical & & 1 & $0.531 * *$ & $-0.422 *$ & $-0.083 *$ & -0.93 & $-0.673 * *$ \\
\hline SF-12 mental & & & I & $-0.4 \mathrm{II} *$ & -0.043 & -0.178 & $-0.76^{* *}$ \\
\hline NDI & & & & 1 & $0.4 I^{*}$ & 0.128 & $0.52 * *$ \\
\hline VAS & & & & & I & 0.088 & 0.133 \\
\hline STAI & & & & & & 1 & -0.028 \\
\hline BECK & & & & & & & 1 \\
\hline \multicolumn{8}{|c|}{ Neck pain with temporomandibular dysfunction } \\
\hline SF-I 2 total & I & $0.909 * *$ & $0.873^{* *}$ & $-0.637 * *$ & $-0.474 *$ & -0.125 & $-0.389 *$ \\
\hline SF-I 2 physical & & 1 & $0.591 * *$ & $-0.583 * *$ & $-0.425^{*}$ & 0.256 & -0.299 \\
\hline SF-I 2 mental & & & I & $-0.55 I * *$ & $-0.414 *$ & -0.057 & $-0.406^{*}$ \\
\hline NDI & & & & 1 & $0.442 * *$ & -0.026 & 0.211 \\
\hline VAS & & & & & 1 & 0.026 & -0.227 \\
\hline STAI & & & & & & 1 & 0.225 \\
\hline BECK & & & & & & & I \\
\hline
\end{tabular}

Notes: $* p<0.05 ; * * p<0.01$.

Abbreviations: NDI, Neck Disability Index; VAS, visual analog scale; BECK, Beck Depression Inventory; STAI, State-Trait Anxiety Inventory; SF-I2, Short Form-I2 Health Survey.

realm. This differs with our regression model, which showed that depression on its own (65.9\% of variance) and depression associated with anxiety $(70.3 \%$ of variance) were significant predictors of extreme HRQoL. Depression itself was a predictor in our results, but not in those of Lantéri-Minet et al ${ }^{59}$ which may be due to the association of NP in our sample. Furthermore, due to a lack of studies on HRQoL for migraine and NP subjects, we could not compare our results with other studies.

Previous research also did not compare HRQoL in patients with TMD or TMD associated with NP. Thus, the data presented in this study suggest that neck disability, pain intensity, and anxiety are negatively correlated with the physical sphere of HRQoL - while only neck disability has been negatively correlated with the mental sphere of HRQoL.
Total HRQoL was the independent variable used in multiple linear regression models for this study. According to this, the CNP (48.9\% of variance) and NP-TMD (48.4\% of variance) groups' neck disability significantly predicted the worst kind of HRQoL. Depression was similarly a significant predictor of the worst HRQoL in the WHIP (31.7\% of variance) and NP-PH (65.9\% of variance) groups. These data may offer clues to clinicians about what could be included in treatment for an optimally effective approach.

\section{Limitations}

This study has several limitations: first was the lack of a control group, precluding the possibility of assessing the QoL in comparison to the healthy population - and to see if the HRQoL of patients with NP was worse; however, we were aware that HRQoL in NP patients was considerably 
Table 3 Regression model for SF- 2 total in each neck pain group

\begin{tabular}{|c|c|c|c|c|c|}
\hline \multicolumn{6}{|c|}{ Criterion variable: SF-I 2} \\
\hline \multicolumn{6}{|l|}{ Group } \\
\hline \multirow[t]{8}{*}{ CNP } & \multicolumn{5}{|c|}{ Overall model } \\
\hline & \multicolumn{5}{|c|}{$R^{2}=0.5$, adjusted $R^{2}=0.489, F=44.943$} \\
\hline & $\begin{array}{l}\text { Predictor } \\
\text { variables }\end{array}$ & $\begin{array}{l}\text { Regression } \\
\text { coefficient (B) }\end{array}$ & $\begin{array}{l}\text { Standardized } \\
\text { coefficient }(\beta)\end{array}$ & $P$-value & VIF \\
\hline & NDI & -2.343 & -0.707 & $<0.001 * *$ & 1.00 \\
\hline & $\begin{array}{l}\text { Excluded } \\
\text { variables }\end{array}$ & & & & \\
\hline & BECK & - & -0.188 & 0.186 & 1.806 \\
\hline & STAI & - & -0.019 & $0.86 \mathrm{I}$ & 1.064 \\
\hline & VAS & - & -0.038 & 0.728 & 1.021 \\
\hline \multirow[t]{8}{*}{ WHIP } & \multicolumn{5}{|c|}{ Overall model } \\
\hline & \multicolumn{5}{|c|}{$R^{2}=0.33$, adjusted $R^{2}=0.317, F=25.145$} \\
\hline & $\begin{array}{l}\text { Predictor } \\
\text { variables }\end{array}$ & $\begin{array}{l}\text { Regression } \\
\text { coefficient (B) }\end{array}$ & $\begin{array}{l}\text { Standardized } \\
\text { coefficient ( } \beta \text { ) }\end{array}$ & $P$-value & VIF \\
\hline & BECK & -1.182 & -0.236 & $<0.00 I^{* *}$ & 1.00 \\
\hline & $\begin{array}{l}\text { Excluded } \\
\text { variables }\end{array}$ & & & & \\
\hline & NDI & - & -0.226 & 0.096 & 1.396 \\
\hline & STAI & - & -0.184 & 0.108 & 1.00 \\
\hline & VAS & - & 0.97 & 0.426 & 1.098 \\
\hline \multirow[t]{8}{*}{ NP-HP } & \multicolumn{5}{|c|}{ Overall model } \\
\hline & \multicolumn{5}{|c|}{$R^{2}=0.78 \mathrm{I}$, adjusted $R^{2}=0.75 \mathrm{I}, F=26.187$} \\
\hline & $\begin{array}{l}\text { Predictor } \\
\text { variables }\end{array}$ & $\begin{array}{l}\text { Regression } \\
\text { coefficient (B) }\end{array}$ & $\begin{array}{l}\text { Standardized } \\
\text { coefficient ( } \beta \text { ) }\end{array}$ & $P$-value & VIF \\
\hline & BECK & -1.758 & -0.907 & $<0.001 * *$ & 1.084 \\
\hline & STAI & -0.85 & -0.253 & $0.02 *$ & 1.017 \\
\hline & VAS & 0.321 & 0.243 & $0.028 *$ & 1.077 \\
\hline & $\begin{array}{l}\text { Excluded } \\
\text { variables }\end{array}$ & & & & \\
\hline & NDI & - & 0.118 & 0.366 & 1.633 \\
\hline \multirow[t]{8}{*}{ NP-TMD } & \multicolumn{5}{|c|}{ Overall model } \\
\hline & \multicolumn{5}{|c|}{$R^{2}=0.505$, adjusted $R^{2}=0.484, F=23.495$} \\
\hline & $\begin{array}{l}\text { Predictor } \\
\text { variables }\end{array}$ & $\begin{array}{l}\text { Regression } \\
\text { coefficient (B) }\end{array}$ & $\begin{array}{l}\text { Standardized } \\
\text { coefficient }(\beta)\end{array}$ & $P$-value & VIF \\
\hline & NDI & -2.573 & -0.711 & $<0.001 * *$ & 1.00 \\
\hline & $\begin{array}{l}\text { Excluded } \\
\text { variables }\end{array}$ & & & & \\
\hline & BECK & - & -0.158 & 0.302 & 1.048 \\
\hline & STAI & - & 0.238 & 0.108 & 1.012 \\
\hline & VAS & - & -0.130 & 0.462 & 1.375 \\
\hline
\end{tabular}

Notes: $* p<0.05 ; * * p<0.01$.

Abbreviations: VIF, variance inflation factor; CNP, chronic neck pain; WHIP, neck pain associated with acute whiplash; NP-PH, neck pain associated with chronic primary headache; NP-TMD, neck pain associated with temporomandibular dysfunction; NDI, Neck Disability Index; VAS, visual analog scale; BECK, Beck Depression Inventory; STAI, State-Trait Anxiety Inventory; SF-12, Short Form- I2 Health Survey.

lower than that of the general population (vs other study results). ${ }^{29}$ The second involved education and occupation in the sample, which were not included as sociodemographic cofounders; this should be considered for future research, as other studies report on this for NP. ${ }^{60}$ Furthermore, there were moderately positive correlations for ranges of motion and health quality in patients with CNP and NP-TMD, but we could not perform a regression analysis, as our sample 
size was too small and only four variables could be included (NDI, VAS, STAI, and BECK).

In the future, the authors will consider other predictors that could influence HRQoL, but in this study we could not do so due to an excess of predictors. Continued studies will include other psychological scales and determine the effect of certain patient aspects. Despite that all outcome measurements were assessed with validated and reliable tools and measurement protocols, there was bias due to the Hawthorne effect (secondary to the patient's surveillance), which may modify normal conduct after being observed. To control for this bias, a detailed explanation protocol for each test will be performed with specific instructions, discussed by assessors with patients under the same conditions. ${ }^{61}$

\section{Implications}

On the one hand, this study yields data on the HRQoL of different types of NP, which can be used in clinical practice and research. On the other hand, future studies should discuss these results and continue to study the HRQoL of different kinds of etiologies associated with NP. Regarding the clinical implication of this study (according to our prediction models), interventions to improve neck functionality should be a key focus of patient treatment for CNP and NP-TMD, while psychological interventions to reduce depression and anxiety should be a main focus for WHIP and NP-H. The HRQoL of patients with NP may be improved by interdisciplinary health teams to achieve adequate diagnosis, management, and sustainable outcomes. ${ }^{34}$

\section{Conclusion}

We found that chronic nonspecific NP and chronic NP associated with TMD predict neck disability. For patients with WHIP or primary headache associated with CNP, HRQoL can be anticipated by depression, anxiety, and pain. These results should be interpreted with caution, especially when a therapeutic approach is recently included.

\section{Availability of data and material}

Please contact corresponding author for data requests.

\section{Author contributions}

Authors declare that they participated in the conception or design of the work (HBA, ILUV, RLT, and JFC), the acquisition (HBA and AGM), analysis (HBA, RLT, and JFC), or interpretation of data for the work (CCL, RCC, and DFA); drafting the work or revising it critically for important intellectual content (HBA, ILUV, RLT, JFC, CCL, AGM, RCC, and DFA); and final approval of the version to be published (HBA, ILUV, RLT, JFC, CCL, AGM, RCC, and DFA).

\section{Disclosure}

The authors report no conflicts of interest in this work.

\section{References}

1. Hoy D, March L, Woolf A, et al. The global burden of neck pain: estimates from the global burden of disease 2010 study. Ann Rheum Dis. 2014;73(7):1309-1315.

2. Carroll LJ, Holm LW, Hogg-Johnson S, et al. Course and prognostic factors for neck pain in whiplash-associated disorders (WAD). Spine (Phila Pa 1976). 2008;33(Neck Pain Suppl):S83-S92.

3. Hogg-Johnson S, van der Velde G, Carroll LJ, et al. The burden and determinants of neck pain in the general population: results of the Bone and Joint Decade 2000-2010 Task Force on Neck Pain and Its Associated Disorders. J Manipulative Physiol Ther. 2009;32(2 Suppl): S46-S60.

4. Palacios-Ceña D, Alonso-Blanco C, Hernández-Barrera V, CarrascoGarrido P, Jiménez-García R, Fernández-de-Las-Peñas C. Prevalence of neck and low back pain in community-dwelling adults in Spain: an updated population-based national study (2009/10-2011/12). Eur Spine J. 2015;24(3):482-492.

5. Haldeman S, Carroll L, Cassidy JD. Findings from the bone and joint decade 2000 to 2010 task force on neck pain and its associated disorders. J Occup Environ Med. 2010;52(4):424-427.

6. Carroll LJ, Hogg-Johnson S, van der Velde G, et al. Course and prognostic factors for neck pain in the general population: results of the Bone and Joint Decade 2000-2010 Task Force on Neck Pain and Its Associated Disorders. J Manipulative Physiol Ther. 2009;32(2 Suppl):S87-S96.

7. Ashina S, Bendtsen L, Lyngberg AC, Lipton RB, Hajiyeva N, Jensen R. Prevalence of neck pain in migraine and tension-type headache: a population study. Cephalalgia. 2015;35(3):211-219.

8. da Costa DRA, de Lima Ferreira AP, Pereira TAB, et al. Neck disability is associated with masticatory myofascial pain and regional muscle sensitivity. Arch Oral Biol. 2015;60(5):745-752.

9. Verhagen AP, Lewis M, Schellingerhout JM, et al. Do whiplash patients differ from other patients with non-specific neck pain regarding pain, function or prognosis? Man Ther. 2011;16(5):456-462.

10. La Touche R, París-Alemany A, Mannheimer JS, et al. Does mobilization of the upper cervical spine affect pain sensitivity and autonomic nervous system function in patients with cervico-craniofacial pain?: a randomized-controlled trial. Clin J Pain. 2013;29(3):205-215.

11. Lampl C, Rudolph M, Deligianni CI, Mitsikostas DD. Neck pain in episodic migraine: premonitory symptom or part of the attack? J Headache Pain. 2015;16(1):566.

12. Landgraf MN, von Kries R, Heinen F, Langhagen T, Straube A, Albers L. Self-reported neck and shoulder pain in adolescents is associated with episodic and chronic migraine. Cephalalgia. 2016;36(8):807-811.

13. Ferracini GN, Chaves TC, Dach F, Bevilaqua-Grossi D, Fernández-deLas-Peñas C, Speciali JG. Relationship between active trigger points and head/neck posture in patients with migraine. Am J Phys Med Rehabil. 2016;95(11):831-839.

14. Ferracini GN, Florencio LL, Dach F, et al. Musculoskeletal disorders of the upper cervical spine in women with episodic or chronic migraine. Eur J Phys Rehabil Med. 2017;53(3):342-350.

15. Gonçalves MC, Chaves TC, Florencio LL, et al. Is pressure pain sensitivity over the cervical musculature associated with neck disability in individuals with migraine? J Bodyw Mov Ther. 2015;19(1):67-71.

16. Bahat HS, Weiss P, Sprecher E. Do neck kinematics correlate with pain intensity, neck disability or with fear of motion? Man Ther. 2014; 19(3):252-258. 
17. Breivik H, Collett B, Ventafridda V, Cohen R, Gallacher D. Survey of chronic pain in Europe: prevalence, impact on daily life, and treatment. Eur J Pain. 2006;10(4):287-333.

18. Pool JJM, Ostelo RWJG, Knol D, Bouter LM, de Vet HCW. Are psychological factors prognostic indicators of outcome in patients with sub-acute neck pain? Man Ther. 2010;15(1):111-116.

19. Williamson E, Williams MA, Gates S, Lamb SE. Risk factors for chronic disability in a cohort of patients with acute whiplash associated disorders seeking physiotherapy treatment for persisting symptoms. Physiotherapy. 2015;101(1):34-43.

20. Young SB, Aprill C, Braswell J, Ogard WK, Richards JS, McCarthy JP. Psychological factors and domains of neck pain disability. Pain Med. 2009; 10(2):310-318

21. Carroll LJ, Holm LW, Ferrari R, Ozegovic D, Cassidy JD. Recovery in whiplash-associated disorders: do you get what you expect? J Rheumatol. 2009;36(5):1063-1070.

22. Walton DM, Pretty J, MacDermid JC, Teasell RW. Risk factors for persistent problems following whiplash injury: results of a systematic review and meta-analysis. J Orthop Sports Phys Ther. 2009; 39(5):334-350.

23. Sterling M, Hendrikz J, Kenardy J, et al. Assessment and validation of prognostic models for poor functional recovery 12 months after whiplash injury: a multicentre inception cohort study. Pain. 2012;153(8): 1727-1734.

24. Devan D, Ukzn B, Therapy H. A review of current therapeutic practice for the management of chronic pain. South African J Occup Ther. 2014;44(1):48-50.

25. Yalcinkaya H, Ucok K, Ulasli AM, et al. Do male and female patients with chronic neck pain really have different health-related physical fitness, depression, anxiety and quality of life parameters? Int J Rheum Dis. 2017;20(9):1079-1087.

26. Nolet PS, Côté P, Kristman VL, Rezai M, Carroll LJ, Cassidy JD. Is neck pain associated with worse health-related quality of life 6 months later? A population-based cohort study. Spine J. 2015;15(4): 675-684.

27. Pedisic Z, Pranic S, Jurakic D. Relationship of back and neck pain with quality of life in the Croatian general population. J Manipulative Physiol Ther. 2013;36(5):267-275.

28. Salo P, Ylönen-Käyrä N, Häkkinen A, Kautiainen H, Mälkiä E, Ylinen J. Effects of long-term home-based exercise on health-related quality of life in patients with chronic neck pain: a randomized study with a 1-year follow-up. Disabil Rehabil. 2012;34(23):1971-1977.

29. Hammerlid E, Taft C. Health-related quality of life in long-term head and neck cancer survivors: a comparison with general population norms Br J Cancer. 2001;84(2):149-156.

30. Wallin MKM, Raak RI. Quality of life in subgroups of individuals with whiplash associated disorders. Eur J Pain. 2008;12:842-849.

31. Lin R-F, Chang J-J, Lu Y-M, Huang M-H, Lue Y-J. Correlations between quality of life and psychological factors in patients with chronic neck pain. Kaohsiung J Med Sci. 2010;26(1):13-20.

32. Takasawa E, Yamamoto A, Kobayashi T, et al. Characteristics of neck and shoulder pain in the Japanese general population. J Orthop Sci. 2015;20(2):403-409.

33. Leaver AM, Maher CG, McAuley JH, Jull GA, Refshauge KM. Characteristics of a new episode of neck pain. Man Ther. 2013;18(3): 254-257.

34. Manolopoulos L, Vlastarakos PV, Georgiou L, Giotakis I, Loizos A, Nikolopoulos TP. Myofascial pain syndromes in the maxillofacial area: a common but underdiagnosed cause of head and neck pain. Int J Oral Maxillofac Surg. 2008;37(11):975-984.

35. Headache Classification Subcommittee of the International Headache Society. The International Classification of Headache Disorders: 2nd edition. Cephalalgia. 2004;24(Suppl 1):9-160.

36. Headache Classification Committee of the International Headache Society (IHS). The International Classification of Headache Disorders, 3rd edition (beta version). Cephalalgia. 2013;33(9):629-808.
37. Schiffman E, Ohrbach R, Truelove E, et al. Diagnostic Criteria for Temporomandibular Disorders (DC/TMD) for Clinical and Research Applications: recommendations of the International RDC/TMD Consortium Network* and Orofacial Pain Special Interest Group $†$. J Oral Facial Pain Headache. 2014;28(1):6-27.

38. Wolfe F, Clauw DJ, Fitzcharles M-A, et al. The American College of Rheumatology preliminary diagnostic criteria for fibromyalgia and measurement of symptom severity. Arthritis Care Res (Hoboken). 2010;62(5):600-610.

39. Maruish ME, DeRosa MA. A Guide to the Integration of Certified Short Form Survey Scoring and Data Quality Evaluation Capabilities. Lincoln, RI: Quality Metric Incorporated; 2009.

40. Brazier JE, Roberts J. The estimation of a preference-based measure of health from the SF-12. Med Care. 2004;42(9):851-859.

41. Vilagut G, Valderas JM, Ferrer M, Garin O, López-García E, Alonso J. Interpretación de los cuestionarios de salud SF-36 y SF-12 en España: componentes físico y mental [Interpretation of SF-36 and SF-12 questionnaires in Spain: physical and mental components]. Med Clin (Barc). 2008;130(19):726-735. Spanish.

42. Gandek B, Ware JE, Aaronson NK, et al. Cross-validation of item selection and scoring for the SF-12 Health Survey in nine countries: results from the IQOLA Project. International Quality of Life Assessment. J Clin Epidemiol. 1998;51(11):1171-1178.

43. Vernon H. The Neck Disability Index: state-of-the-art, 1991-2008. J Manipulative Physiol Ther. 2008;31(7):491-502.

44. MacDermid JC, Walton DM, Avery S, et al. Measurement properties of the neck disability index: a systematic review. J Orthop Sports Phys Ther. 2009;39(5):400-417.

45. Kovacs FM, Bagó J, Royuela A, et al. Psychometric characteristics of the Spanish version of instruments to measure neck pain disability. BMC Musculoskelet Disord. 2008;9(1):42.

46. Andrade Ortega JA, Delgado Martínez AD, Almécija Ruiz R. Validation of the Spanish version of the Neck Disability Index. Spine (Phila Pa 1976). 2010;35(4):E114-E118.

47. Jensen MP, Turner JA, Romano JM, Fisher LD. Comparative reliability and validity of chronic pain intensity measures. Pain. 1999;83(2): $157-162$.

48. Katz J, Melzack R. Measurement of pain. Surg Clin North Am. 1999; 79(2):231-252.

49. Guillén-Riquelme A, Buela-Casal G. Actualización psicométrica y funcionamiento diferencial de los ítems en el State Trait Anxiety Inventory (STAI) [Psychometric revision and differential item functioning in the State Trait Anxiety Inventory (STAI)]. Psicothema. 2011;23(3): 510-515. Spanish.

50. Bieling PJ, Antony MM, Swinson RP. The State-Trait Anxiety Inventory, Trait version: structure and content re-examined. Behav Res Ther. 1998;36(7-8):777-788.

51. Börsbo B, Peolsson M, Gerdle B. Catastrophizing, depression, and pain: correlation with and influence on quality of life and health - a study of chronic whiplash-associated disorders. J Rehabil Med. 2008;40(7):562-569.

52. Mäntyselkä P, Lupsakko T, Kautiainen H, Vanhala M. Neck-shoulder pain and depressive symptoms: a cohort study with a 7-year follow-up. Eur J Pain. 2010;14(2):189-193.

53. Fletcher JP, Bandy WD. Intrarater reliability of CROM measurement of cervical spine active range of motion in persons with and without neck pain. J Orthop Sports Phys Ther. 2008;38(10):640-645.

54. Faul F, Erdfelder E, Lang A-G, Buchner A. G*Power 3: a flexible statistical power analysis program for the social, behavioral, and biomedical sciences. Behav Res Methods. 2007;39(2):175-191.

55. Mukaka MM. Statistics corner: a guide to appropriate use of correlation coefficient in medical research. Malawi Med J. 2012;24(3):69-71.

56. Bragatto MM, Bevilaqua-Grossi D, Regalo SCH, Sousa JD, Chaves TC. Associations among temporomandibular disorders, chronic neck pain and neck pain disability in computer office workers: a pilot study. J Oral Rehabil. 2016;43(5):321-332. 
57. Obermann M, Nebel K, Riegel A, et al. Incidence and predictors of chronic headache attributed to whiplash injury. Cephalalgia. 2010; 30(5):528-534.

58. Kenardy J, Heron-Delaney M, Warren J, Brown E. The effect of mental health on long-term health-related quality of life following a road traffic crash: results from the UQ SuPPORT study. Injury. 2014;36:4-11.

59. Lantéri-Minet M, Radat F, Chautard MH, Lucas C. Anxiety and depression associated with migraine: influence on migraine subjects' disability and quality of life, and acute migraine management. Pain. 2005;118(3):319-326.
60. Nolet PS, Côté P, Kristman VL, Rezai M, Carroll LJ, Cassidy JD. Is neck pain associated with worse health related quality of life six months later? A population-based cohort study. Spine J. 2014;15(4):675-684.

61. Abdulraheem S, Bondemark L. Hawthorne effect reporting in orthodontic randomized controlled trials: truth or myth? Blessing or curse? Eur J Orthod. Epub 2017 Nov 28.

62. von Elm E, Altman DG, Egger M, Pocock SJ, Gotzsche PC, Vandenbroucke JP. The Strengthening the Reporting of Observational Studies in Epidemiology (STROBE) statement: guidelines for reporting observational studies. Ann Intern Med. 2007;147(8):573-577.

\section{Publish your work in this journal}

Patient Preference and Adherence is an international, peer-reviewed, open access journal that focuses on the growing importance of patient preference and adherence throughout the therapeutic continuum. Patient satisfaction, acceptability, quality of life, compliance, persistence and their role in developing new therapeutic modalities and compounds to optimize clinical outcomes for existing disease states are major areas of interest for the journal. This journal has been accepted for indexing on PubMed Central. The manuscript management system is completely online and includes a very quick and fair peer-review system, which is all easy to use. Visit http://www dovepress.com/testimonials.php to read real quotes from published authors.

Submit your manuscript here: http://www.dovepress.com/patient-preference-and-adherence-journal 